\title{
Studi Pengaruh Warna pada Interior Terhadap Psikologis Penggunanya, Studi Kasus pada Unit Transfusi Darah Kota $X$
}

\author{
IH Marysa ${ }^{1}$, AW Anggraita ${ }^{1}$ \\ 1,2 Jurusan Desain Interior, Institut Teknologi Sepuluh Nopember,Surabaya 60111, Indonesia \\ 1intanhannahmarysa@gmail.com,2aria.weny@yahoo.com
}

\begin{abstract}
ABSTRAK
Donor darah adalah kegiatan seseorang memberikan darah secara sukarela, kemudian diproses kelayakannya dan ditranfusikan kepada pasien yang membutuhkan. Dalam proses donor darah terdapat tindakan-tindakan medis seperti penyadapan darah melalui jarum sebagai saluran untuk memnyalurkan darah dari pembuluh darah kedalam kantong darah. Tindakan medis yang demikian memberikan efek samping pada pendonor yaitu rasa sakit akibat penyadapan darah melalui jarum. Hal tersebut menjadi sebuah kontradiksi bagi seseorang yang ingin mendonorkan darahnya karena terbayang akan rasa sakit yang ditimbulkan akibat proses penyadapan darah. Untuk mengurangi stress atau ketegangan yang dialami pendonor baik sebelum proses donor darah, dan saat proses donor darah perlu untuk menciptakan suasana yang rileks pada sebuah Unit Transfusi darah. Hal tersebut dapat dilakukan dengan mempertimbangkan aspek desain pada interior Unit Transfusi Darah. Warna adalah salah satu elemen interior yang berpengaruh terhadap psikologi sehingga dapat dipertimbangkan dalam menciptakan sebuah suasana ruang untuk mengurangi ketegangan yang dirasakan pendonor darah.

Penelitian dilakukan dengan cara literatur review dan kuisioner. Studi literatur bertujuan untuk panduan dalam membuat konsep desain, hasil kuisioner digunakan untuk melengkapi studi lapangan tentang karakter pengguna. Hasil penelitian diharapkan mampu menjadi konsep desain interior unit transfusi darah yangdapat memberikan kenyamanan, dan ketenangan pada pendonor agar mampu mereduksi perasaan tegang atau takut pada proses donor darah. Warna warna yang dipilih dikaji berdasarkan fungsi dan emosi penggunanya.
\end{abstract}

Kata kunci : donor darah; desain interior; warna; psikologi

\section{ABSTRACT}

Blood donation is a person's activities to give blood voluntarily, then processed feasibility and transfused into patients in need. In the process of blood donors are medical actions such as tapping the blood through a needle as a channel to transfuse from the blood vessels into the blood bag. Thus providing a medical action on the donor side effects are pain due to blood through needle tapping. It became a contradiction for someone who wants to donate their blood, because of imagined pain caused by blood tapping process. To reduce stress or tension experienced by donors before blood donation process, and during the process of blood donors need to create a relaxed atmosphere in a blood transfusion unit. This can be done by considering aspects of interior design at the Blood Transfusion Unit. Color is one of the elements that influence the psychological interior so as to be considered in creating an atmosphere of space to reduce the tension felt blood donors.

The Research method is literature review and questionnaire collected. Literature review as a guidance to create design concept. Questionnaire data collection aim to know more about users characteristic as a field study. Hopefully this Research result can give more advantages to the users in Surabaya Blood Donation Centre (UTD Surabaya) such as an positive effect to the users psychological, calmness feeling, and comfort feeling, hopefully can reduce tension and fear feeling that appear during transfuse proceed. Color such as important factor for this case will be assessed base on function and users emotion effect.

Keywords : blood donors; interior design; color; psychology 


\section{PENDAHULUAN}

Unit Transfusi Darah (UTD) didirikan oleh PMI untuk melaksanakan tugas khusus dalam hal pelayanan darah, salah satunya adalah UTD PMI Kota X. Pelayanan darah yang difasilitasi oleh UTD PMI meliputi penyediaan darah, pengolahan darah, dan pelayanan donor darah. Dalam prakteknya UTD di Indonesia menyediakan pelayanan donor dengan mempertimbangkan aspek-aspek teknis. Hal tersebut berdampak pada desain interior UTD yang menjadi sangat fungsional dan klinis sehingga kurang mempertimbangkan aspek psikologis pendonor. Berdasarkan Design Guidelines for Blood Donation Centre yang diterbitkan oleh WHO penting untuk membuat sebuah desain non-klinis untuk sebuah UTD, hal tersebut bertujuan memberikan pengalaman donor.

Dalam proses donor darah terdapat tindakan-tindakan medis yang dilakukan salah satunya adalah proses penyadapan darah melalui jarum. Pada proses tersebut setiap pendonor akan mengalami rasa sakit akibat jarum, hal tersebut berdampak pada stigma masyarakat tentang donor darah yaitu rasa sakit yang didapatkan jika mendonorkan darahnya. Stigma tersebut menjadi hal yang penting, sehingga perlu untuk memperhatikan faktor psikologis pendonor darah, yang nantinya mampu memberikan influence pada masyarakat tentang pengalaman donor darah.

Berdasarkan fakta dan pernyataan tersebut kondisi psikologis pendonor darah perlu dipertimbangkan untuk meningkatkan pengalaman donor yang berdampak padak ketertarikan masyarakat untuk mendonorkan darahnya. Hal tersebut dapat dilakukan dengan memberi treatment pada Desain Interior UTD PMI Kota X. Melalui aspek-aspek interior seperti, salah satunya melalui warna atau tones pada ruang yang dapat menciptakan suasana Unit Transfusi Darah yang mampu memberikan perasaan rileks pada pendonor, sehingga berpengaruh pada psikologis pendonor.

\section{METODOLOGI}

Penelitian dilakukan dengan cara literatur review dan kuisioner. Literatur review bertujuan untuk panduan dalam membuat konsep desain, hasil kuisioner digunakan untuk melengkapi studi lapangan tentang karakter pengguna, untuk menegtahui permasalahan melalui pandangan masyarakat terhadap donor darah dan faktor psikologis yang mempengaruhi kenyamanan pendonor darah serta kaitannya terhadap desain interior unit transfuse darah. Melakukan studi terhadap komposisi warna yang akan diterapkan dalam ruang UTD PMI X dan mengaitkan terhadap respon psikologis yang dihasilkan oleh komposisi dan kombinasi warna tersebut.

Guna melengkapi data dan karakter pendonor/pengguna, maka perlu dilakukan pengumpulan data melalui kuisioner. Adapun data yang diperlukan adalah tentang usia, jenis kelamin, status/pekerjaan, tingkat kenyamanan layanan UTD PMI X serta psikologis pendonor.

Tujuan penelitian ini adalah untuk menjadi acuan dalam perancangan desain interior UTD PMI yang dapat memberikan kenyamanan secara psikologis. Selain itu agar UTD PMI mampu meningkatkan loyalitas pendonor yang berdampak pada ketersediaan darah di Indonesia. 


\section{TINJAUAN PUSTAKA}

\section{A. Prosedur Donor Darah}

Dalam melakukan donor darah terdapat proses yang harus dilalui seseorang untuk mengetahui orang tersebut layak menjadi pendonor atau tidak. Berikut adalah alur proses donor darah :

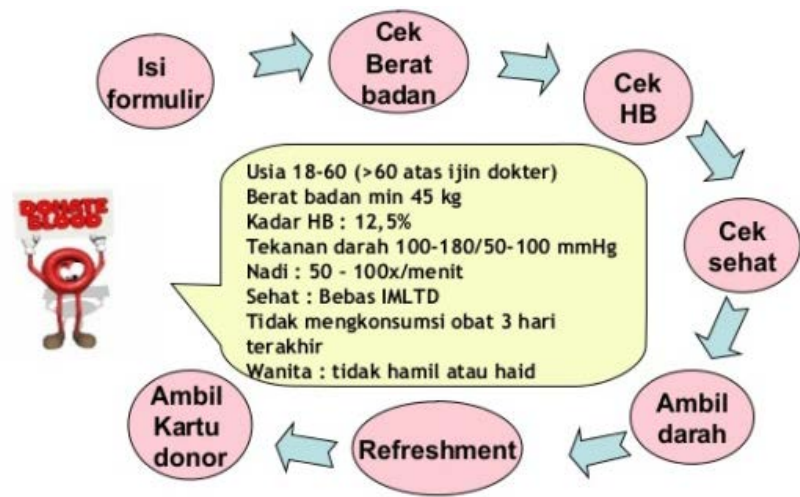

Gambar 1. Prosedur Donor Darah

Sumber : http://www.slideshare.net/AndhikaFrancisco/donor-darah-ppt

Aktivitas yang terjadi dalam prosedur pengambilan darah mempengaruhi kebutuhan ruang pada UTD.Pada UTD PMI Kota $\mathrm{X}$ terdapa truang-ruang yang penting dalam proses donor darah yaitu ruang tunggu, ruang pemeriksaan, ruang AFTAP, dan ruang pemulihan.

\section{B. Psikologi Warna}

Dari sisi psikologi, warna mempunyai pengaruh kuat terhadap suasana hati dan emosi manusia, membuat suasana panas atau dingin, provokatif atau simpati, menggairahkan atau menenangkan. Warna merupakan sebuah sensasi, dihasilkan otak dari cahaya yang masuk melalui mata. Secara fisik sensasi-sensasi dapat dibentuk dari warna-warna yang ada. Sebagai contoh, ruang yang diberi warna putih atau warna-warna lembut lainnya dapat memberikan kesan bahwa ruang tersebut lebih besar dari dimensi yang sebenarnya. Hal sebaliknya akan terjadi jika ruang menggunakan warna-warna gelap. Untuk mendapatkan sensasi hangat yang sama, ruang yang diberi warna-warna dingin memerlukan pengaturan suhu (misalnya dengan air conditioning) yang lebih rendah dibandingkan dengan ruang yang diberikan warna-warna hangat [1].

Ditinjau dari efeknya terhadap kejiwaan dan sifat khas yang dimilikinya, warna dipilah dalam 2 kategori yaitu golongan warna panas dan golongan warna dingin. Diantara keduanya ada yang disebut warna antara atau 'intermediates'. Pada skema warna psikologi (Gambar 2) yang diambil dari system lingkaran warna Oswald dapat dilihat dengan jelas golongan warna panas berpuncak pada warna jingga $(\mathrm{J})$, dan warna dingin berpuncak pada warna biru kehijauan (BH). Warna-warna yang dekat dengan jingga atau merah digolongkan kepada warna panas atau hangat dan warna-warna yang berdekatan dengan warna biru kehijauan termasuk golongan warna dingin atau sejuk [4]. 


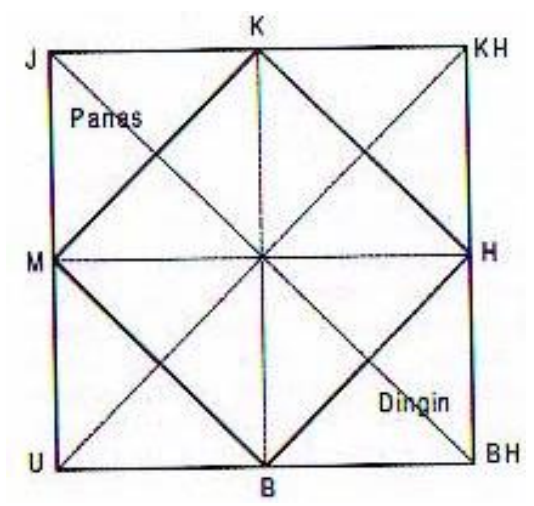

Gambar 2. Skema Psikologi Warna Sumber : Sulasmi (2002)

Efek psikologis golongan warna panas, seperti merah, jingga, dan kuning memberi pengaruh psikologis panas, menggembirakan, menggairahkan dan merangsang (Pile, 1995 dan Birren, 1961). Warna kuning dan turunannya memiliki kesan hangat dan menyenangkan karena warna kuning seperti sinar matahari yang baru terbit sehingga memberi kesan semangat di pagi hari [6]. Golongan warna dingin hijau dan biru memberi pengaruh psikologis menenangkan, damai(Pile, 1995 dan Birren, 1961). Frenchman (2012) mengatakan Warna biru dan turunannya adalah warna yang berlimpah di bumi melambangkan konotasi natural sehingga berkesan damai, tenang, segar, kemurnian dan positive feelings. Warna biru sangat cocok dikombinasikan dengan berbagai macam warna.Warna ungu membawa pengaruh menyedihkan. Untuk warna putih memberi pengaruh bersih, terbuka dan terang, warna hitam memberi pengaruh berat, formal, dan tidak menyenangkan (Pile, 1995 dan Birren, 1961).

\section{HASIL STUDI LAPANGAN}

\section{A. Demografi}

Pendonor darah usia muda adalah seseorang yang berusia 17 tahun hingga 30 tahun. Berdasarkan diagram di atas seluruh responden termasuk dalam kriteria pendonor darah usia muda, hal tersebut dapat dilihat dari rentan usia reponden yaitu dari 17 tahun sampai 24 tahun. Sedangkan untuk rasio usia responden paling tinggi adalah usia 19 tahun, dan 21 tahun dengan jumlah responden pada masing-masing usia adalah 6 orang. Rasio paling rendah adalah pada usia 17 tahun dengan jumlah responden 1 orang.

1. Usia

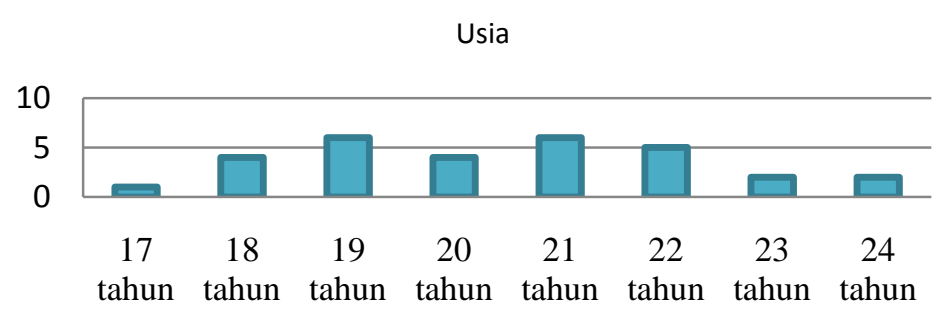

Gambar 3. Diagram Usia Responden 
2. Jenis Kelamin

Tabel 1. Data Jenis Kelamin Responden

\begin{tabular}{|c|c|c|}
\hline Jawaban & Jumlah & Presentase \\
\hline Laki-laki & 8 & $27 \%$ \\
\hline Perempuan & 22 & $73 \%$ \\
\hline Total & $\mathbf{3 0}$ & $\mathbf{1 0 0 \%}$ \\
\hline
\end{tabular}

Berdasarkan Tabel 1 di atas mayoritas responden memiliki jenis kelamin perempuan.

3. Status

Tabel 2. Data Status Responden

\begin{tabular}{|c|c|c|}
\hline Jawaban & Jumlah & Presentase \\
\hline Pelajar/ Mahasiswa & 26 & $87 \%$ \\
\hline Bekerja & 4 & $13 \%$ \\
\hline Total & $\mathbf{3 0}$ & $\mathbf{1 0 0 \%}$ \\
\hline
\end{tabular}

Berdasarkan Tabel 2, mayoritas reponden berstatus sebagai pelajar/mahasiswa.

\section{B. Ketertarikan Pemuda Terhadap Kegiatan Donor Darah.}

1. Banyaknya Responden yang Pernah Melakukan Donor Darah.

Tabel 3. Data Responden yang Pernah Donor Darah

\begin{tabular}{|c|c|c|}
\hline Jawaban & Jumlah & Presentase \\
\hline Belum Pernah & 23 & $77 \%$ \\
\hline Pernah & 7 & $23 \%$ \\
\hline Total & $\mathbf{3 0}$ & $\mathbf{1 0 0 \%}$ \\
\hline
\end{tabular}

Berdasarkan Tabel 3 mayoritas responden belum pernah melakukan donor darah dengan perbandingan jumlah responden yang pernah melakukan donor darah 23 orang, dan yang belum pernah donor 7 orang. Data tersebut mengintrepretasikan bahwa ketertarikan pemuda terhadap kegiatan donor darah masih rendah.

2. Tempat Donor Darah

Tabel 4. Data Tempat Melakukan Donor Darah

\begin{tabular}{|l|c|c|}
\hline \multicolumn{1}{|c|}{ Jawaban } & Jumlah & Presentase \\
\hline Unit Transfusi Darah PMI & 2 & $29 \%$ \\
\hline Event-event tertentu & 4 & $57 \%$ \\
\hline Lainnya & 1 & $14 \%$ \\
\hline Total & $\mathbf{7}$ & $\mathbf{1 0 0 \%}$ \\
\hline
\end{tabular}

Berdasarkan Tabel 4 dari 7 orang responden yang pernah melakukan donor darah, 4 orang responden melakukannya pada event-event tertentu, sedangkan 2 orang melakukannya di UTD PMI Kota X, dan sisanya lainnya.

3. Faktor Tidak Donor Darah

Tabel 5. Data Faktor Tidak Donor Darah

\begin{tabular}{|l|c|c|}
\hline \multicolumn{1}{|c|}{ Jawaban } & Jumlah & Presentase \\
\hline Takut & 16 & $57 \%$ \\
\hline Tidak Memenuhi Syarat & 9 & $32 \%$ \\
\hline Belum Sempat & 3 & $11 \%$ \\
\hline Total & $\mathbf{2 8}$ & $\mathbf{1 0 0 \%}$ \\
\hline
\end{tabular}


Berdasarkan Tabel 5 faktor paling tinggi yang menyebabkan tidak melakukan donor darah adalah takut. Sedangkan yang kedua adalah tidak memenuhinya kriteria responden sebagai pendonor, seperti kriteria kondisi kesehatan responden berat badan kurang, hemoglobin kurang dan lainnya. Faktor terakhir adalah tidak menyempatkannya responden untuk melakukan donor darah. Data tersebut mengintrepretasikan bahwa responden yang tidak melakukan donor darah dikarenakan rasa takut terhadap kegiatan donor darah.

4. Tingkat Kenyamanan Pengunjung pada UTD PMI Kota X.

Tabel 6. Data Tingkat Kenyamanan UTD PMI Kota X

\begin{tabular}{|l|l|l|l|}
\hline \multicolumn{1}{|c|}{ Jawaban } & \multicolumn{1}{|c|}{ Alasan } & Jumlah & Presentase \\
\hline Nyaman & $\begin{array}{l}\text { Pelayanannya cepat, antriannya } \\
\text { tertib }\end{array}$ & 1 & $25 \%$ \\
\cline { 1 - 2 } Cukup Nyaman & Kurang keren bangunannya & 3 & $75 \%$ \\
\cline { 2 - 3 } & Sama seperti PMI pada umumnya & & \\
\cline { 2 - 3 } & Tidak ada desain khusus & 0 & $0 \%$ \\
\hline Kurang Nyaman & - & 0 & $0 \%$ \\
\hline Tidak Nyaman & - & $\mathbf{4}$ & $\mathbf{1 0 0} \%$ \\
\hline \multicolumn{2}{l|}{ Total } &
\end{tabular}

Berdasarkan Tabel 6 dari seluruh responden, yang pernah berkunjung ke UTD PMI hanya 4 orang responden, dan mayoritas responden merasa cukup nyaman dengan kondisi UTD PMI Kota X. Alasan responden menginterpretasikan bahwa kenyamanan yang ditimbulkan dari UTD PMI Kota X berupa hal-hal teknis seperti pelayanan, dan kebersihan.

\section{Psikologis Pendonor}
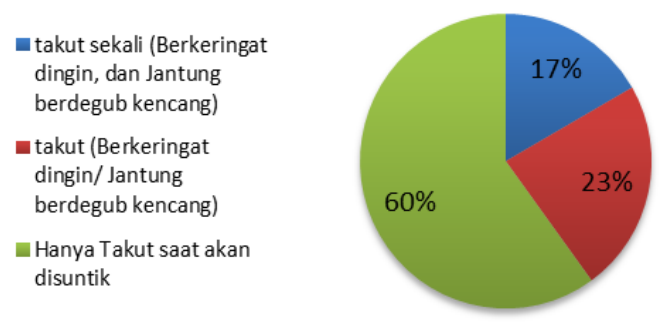

Gambar 4.Diagram Tingkat Rasa TakutPendonor

Berdasarkan hasil survey yang telah dilakukan peneliti tehadap 30 orang pendonor didapatkan hasil bahwa setiap pendonor memiliki perasaan takut pada tingkat yang berbedabeda, seperti nampak pada gambar 4 . Ketika berada diruang tunggu dan ruang pemeriksaan, pendonor memiliki rasa takut tetapi tidak banyak, pada situasi ini pendonor harus merasakan kenyamanan dan keyakinan. Pendonor memiliki rasa takut dengan tingkat ketakutan yang berbeda-beda ketika berada di ruang AFTAF ruang tempat berlangsungnya penyadapan darah. Pada ruang pemulihan pendonor membutuhkan suasana yang segar untuk memulihkan kondisi badannya.

\section{PEMBAHASAN}

Dalam perancangan interior UTD PMI Kota X penting menciptakan suasana ruang untuk membentuk persepsi pendonor yang dapat memberikan perasaan menyenangkan dan 
menenangkan. Berikut studi warna yang dapat diterapkan pada ruang-ruang yang berhubungan langsung dengan pendonor.

\section{A. Ruang Tunggu}

Ruang tunggu merupakan ruang utama pendonor saat tiba di UTD, dalam ruang ini aktivitas yang terjadi adalah pendonor melakukan kegiatan administrasi, dan menunggu panggilan untuk proses berikutnya. Pada ruang ini nuansa yang diciptakan haruslah menyenangkan, dan ramah. Hal tersebut bertujuan untuk mengurangi rasa takut pendonor, dan memberi perasaan disambut.

Nuansa warna yang dapat diterapkan untuk menciptakan efek menenangkan, dan disambut adalah coklat muda. Warna coklat memberikan efek kehangatan, dukungan, dan ketenangan[3].

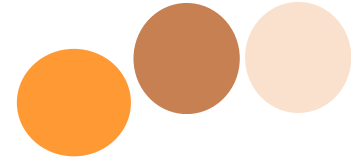

\section{Gambar 5. Palet Warna Coklat}

Keceriaan pada ruang tunggu dapat diciptakan melalui aksentuasi yang ada pada elemen interior dengan memadukan warna-warna yang ada.

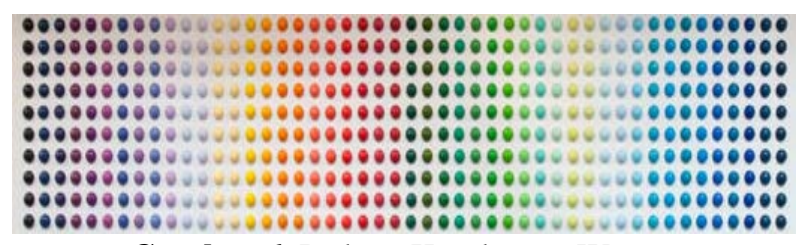

Gambar 6. Paduan Keseluruan Warna

Berikut contoh aplikasi warna coklat dan beberapa paduan warna lainnya pada interior :

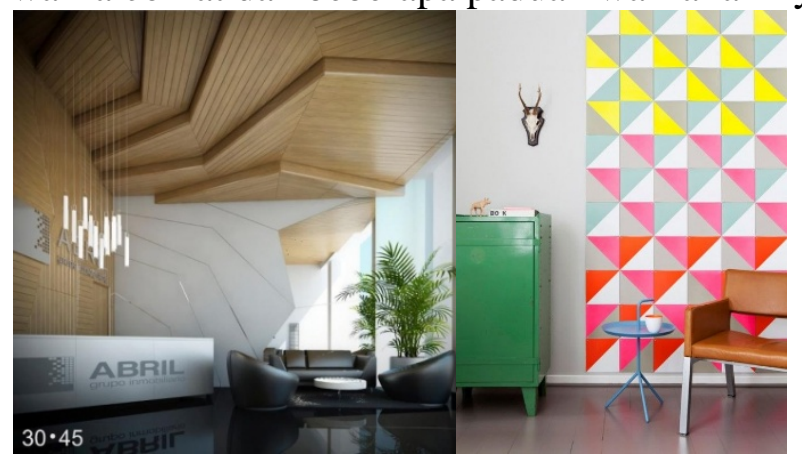

Gambar 7.

Interior dengan Aplikasi Warna Coklat Muda

Sumber : https://www.pinterest.com/
Gambar 8.

Elemen Estetis dengan Paduan Beberapa Warna Sumber : https://www.pinterest.com/

\section{B. Ruang Pemeriksaan}

Pada ruang pemeriksaan aktivitas yang terjadi adalah pendonor diperiksa HB dengan mengambil sampel darah, kemudian melakukan wawancara dengan dokter. Pada proses ini penting menciptakan suasana tenang dan rileks karena ketegangan pendonor meningkat pada tahap ini. Warna yang dapat diterapkan pada ruang ini adalah warna-warna alam khususnya hijau, dan biru. Warna hijau dapat diciptakan melalui tanaman yang digunakan sebagai elemen estetis pada ruangan sedangkan warna biru dapat diterapkan pada elemen interior [3]. 
Warna biru dan turunannya melambangkan konotasi natural sehingga berkesan damai, tenang, segar, kemurnian dan positive feelings [6].

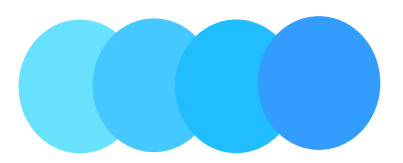

Gambar 9. Palet Warna Biru

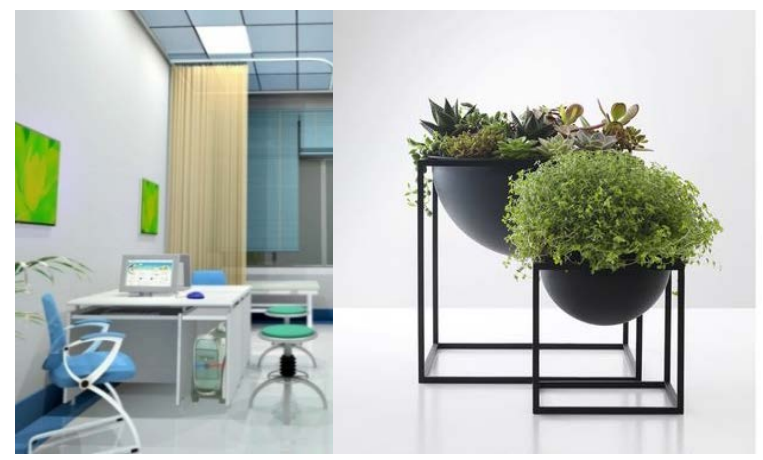

Gambar 10.Contoh Nuansa Ruangan dengan Warna Biru

Sumber :http://www.3dhousedownload.com/
Gambar 11. Warna Hijau Tanaman sebagai Elemen Estetis.

Sumber :https://www.pinterest.com/

\section{Ruang AFTAP}

Ruang AFTAP merupakan ruang tempat berlangsungnya penyadapan darah. Pada proses penyadapan darah pendonor berinteraksi langsung dengan jarum, dan darah. Pada kasus khusus pendonor bisa bereaksi berlebihan pada darah, salah satu contohnya adalah pingsan. Proses penyadapan darah memberikan ketegangan lebih tinggi dibandingkan proses-proses sebelumnya, sehinga pada ruang AFTAP perlu suasana yang benar-benar memberi ketenangan. Pada umumnya warna yang diterapkan adalah putih. Namun warna putih yang terlalu dominan memberikan kesan steril dan dapat membuat pengguna merasa tertekan.

Wright (2008) mengatakan White in effect, it reflects the full force of the spectrum into our eyes. Thus it also creates barriers, but differently from black, and it is often a strain to look at. It communicates, "Touch me not!" White is purity and, like black, uncompromising; it is clean, hygienic, and sterile. Visually, white gives a heightened perception of space. The negative effect of white on warm colors is to make them look and feel garish.

Bila ruangan terlalu banyak bahkan sangat banyak menggunakan warna putih maka akan timbul efek monoton yang secara psikologis menimbulkan kesan tertekan. Namun warna putih bila dikombinasikan dengan warna lain seperti warna pastel dapat memiliki efek kalem, tenang dan harmoni [6], sebagai penyeimbang warna-warna kalem lainnya (turunan warna biru dan hijau yang lembut).

Sehingga warna yang dapat diterapkan pada ruangan ini adalah warna alam yaitu gradasi antara warna biru, dan hijau dengan intensitas warna lembut atau cerah dengan kombinasi warna putih. Warna hijau memberikan suasana menenangkan, sedangkan biru menjaga perasaan agar tetap tenang, dan segar. 


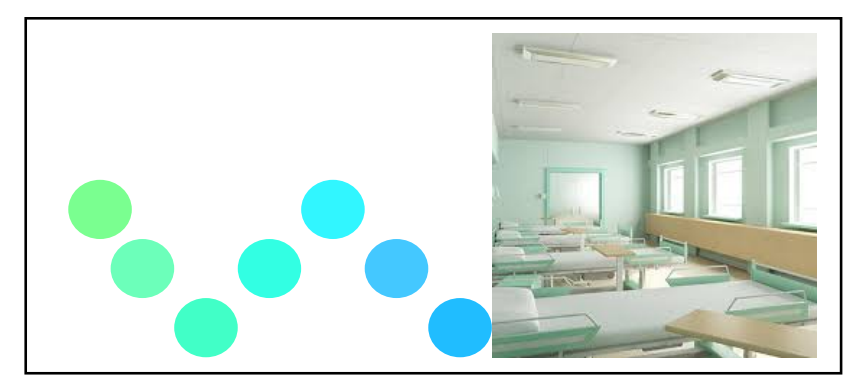

Gambar 12. GradasiWarna antara Hijau dan Biru dan Aplikasinya pada Interior Rumah Sakit. Sumber : http://www.3dhousedownload.com/

\section{Ruang Pemulihan}

Ruang pemulihan berfungsi sebagai tempat dimana pendonor menstabilkan kondisi fisiknya, karena efek dari pasca donor membuat beberapa orang mengalami rasa lemas karena berkurangnya darah dalam tubuh. Oleh karena itu penting pada ruang ini membuat orang ingin menyediakan waktu untuk beristirahat. Warna-warna yang dapat diterapkan pada ruangan ini adalah warna yang dapat memberi pengaruh menyenangkan, dan memberi perasaan fresh. Warna yang dianjurkan adalah dominasi warna dingin (Gambar 13) yang memberikan efek psikologis fresh, dan warnadari golongan warna panas yang dapat membangkitkan semangat. Hal tersebut bertujuan untuk mempercepat pemulihan yang dilakukan pendonor [2][3].

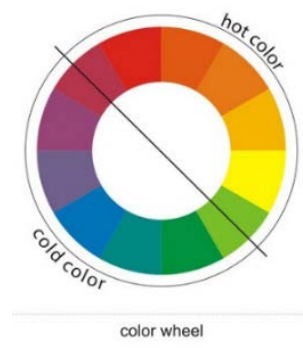

Gambar 13. Skema Warna Munsell

Sumber : http://anak-lingkungan.blogspot.co.id/2015/04/warna.html

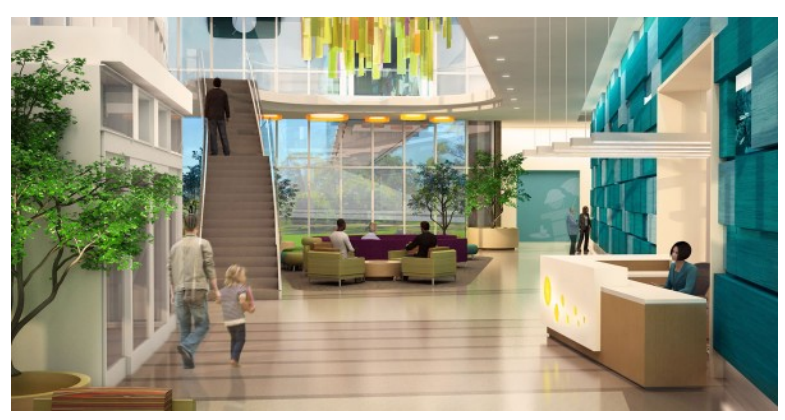

Gambar 14. Contoh Nuansa Ruangan dengan Dominasi Warna Dingin dan Warna Panas sebagai Aksentuasi. Sumber :http://building.akronchildrens.org/

\section{KESIMPULAN}

Berdasarkan fakta bahwa ketersediaan darah di Indonesia belum memenuhi standart yang ditetapkan. Maka perlu menciptakan suasana pada UTD yang dapat memberi ketertarikan, dan 
meningkatkan loyalitas pendonor darah. Oleh karena itu dalam merancang UTD faktor nonmedis seperti psikologis pendonor juga menjadi prioritas.

Interior pada suatu ruangan merupakan hal penting dalam membangun persepsi pengguna karena memiliki dampak psikologis secara langsung. Warna adalah salah stimulus visual yang memiliki pengaruh cukup besar pada psikologi pengguna. Oleh karena itu berdasarkan fungsinya keseluruhan ruang pada unit transfusi darah harus mampu meberikan kenyamanan, dan ketenangan pada pendonor agar mampu mereduksi perasaan tegang atau takut pada proses donor darah.

Warna-warna yang dikategorikan dapat menstimulus rasa tenang, rileks dan nyaman adalah ruang dengan dominasi warna warna sejuk/dingin, dikombinasi dengan warna putih yang memiliki kesan bersih dan tenang. Untuk ruang tunggu, menggunakan warna aksentuasi coklat sebagai warna yang memberi kesan hangat agar tercipta kesan nyaman. Komposisi warna secara garis besar seperti pada gambar berikut:

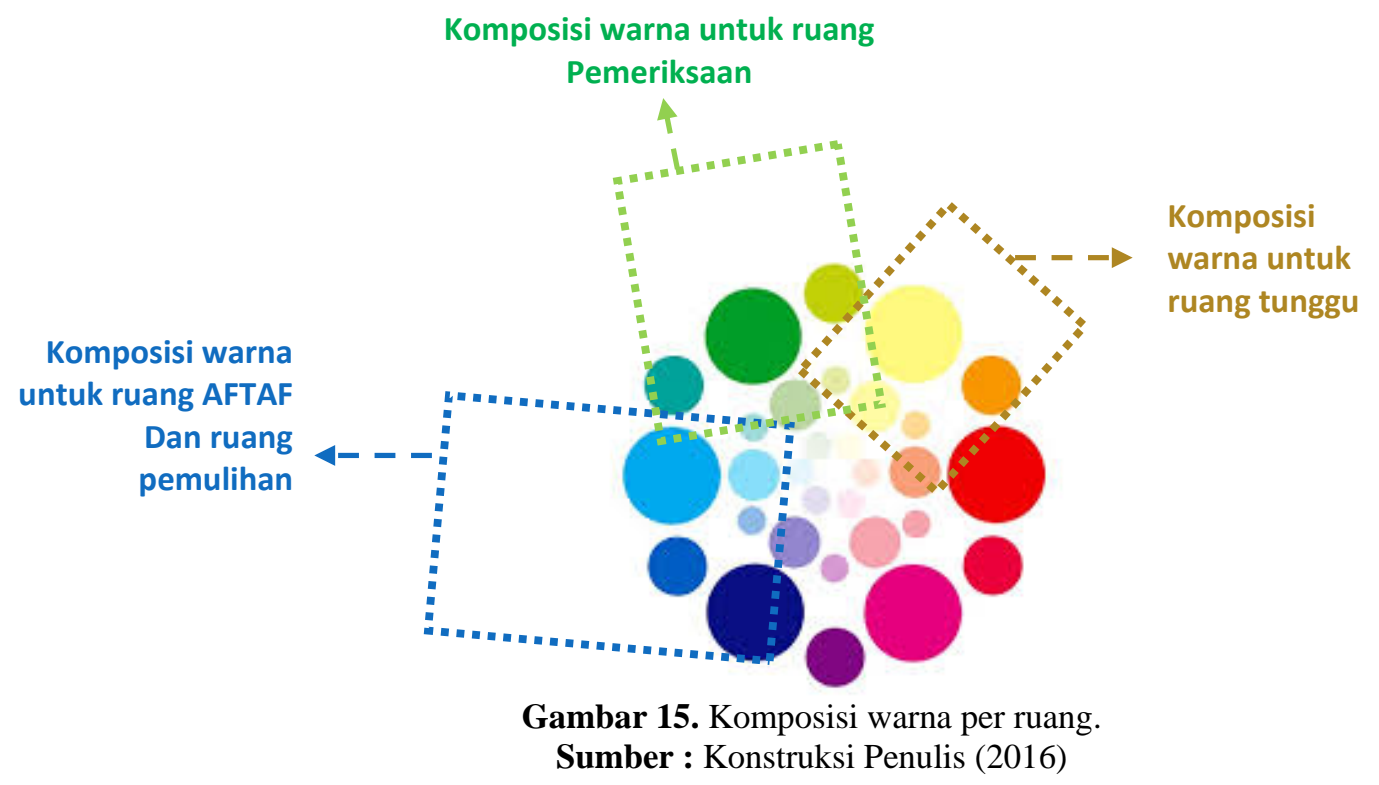

\section{PUSTAKA}

[1] Sari, Sriti Mayang. (2004). Peran Warna pada Interior Rumah Sakit Berwawasan 'Healing Environment' Terhadap Proses Penyembuhan Pasien.http://dimensiinterior.petra.ac.id/index.php/int/article/download/16241/16233.

[2] Lituhayu, Cahaya. (2012). Pengaruh Warna Terhadap Psikologi Pengguna dalam Perancangan Fasilitas Bedah Plastik Estetik, http://jurnals1.fsrd.itb.ac.id/index.php/interior/article/view /25/23 Vol. 1 No.1.

[3] Wright, a. (2008). Psychological Properties of Polours. Diambil Kembali dari Colour Affects:http://www.colour-affects.co.uk/the-colour-affects-system

[4] Darmaprawira, Sulasmi. (2013). Warna : Teori dan Kreativitas Penggunaannya. Bandung : ITB

[5] Goethe, J. W. (2006). Theory of Colours.Dover Publications Inc.

[6] Frechmann. (2014). 500 trick :Color. 